\title{
Service-Oriented Business Design for IT students
}

\author{
Blagovesta Pirelli \\ LAMS, IC \\ École Polytechnique Fédéral de Lausanne, EPFL \\ Lausanne, Switzerland \\ blagovesta.pirelli@epfl.ch
}

\author{
Alain Wegmann \\ LAMS, IC \\ École Polytechnique Fédéral de Lausanne, EPFL \\ Lausanne, Switzerland \\ alain.wegmann@epfl.ch
}

\begin{abstract}
In this Full Innovative Practice Paper, we present a teaching approach, based on service science, for integrating a business curriculum in the engineering educational program. Our approach is a composition of experiential learning, systems thinking, and service-oriented architecture. In the course, students have less content (e.g., a few heuristics to analyze a business environment) to master, but they apply it in different contexts (e.g., written case studies, presentations from live lectures, students' own projects). Our study shows that paced repetition of the same technique with different emotional connectedness to the subject under analysis enables students to practice the same skill without experiencing boredom of repetition, hence, they continue practicing. The service-oriented heuristics teach students how, with the help of a service canvas and an online tool, to analyze businesses and to recognize the role of IT in a business environment. Students demonstrate a higher propensity to master new knowledge when they embody their experience and feel cognitively closer to the studied materials. Further results show that the acquired service-oriented mindset helps students to reuse their learnings in other contexts.
\end{abstract}

Keywords—service science, systems thinking, experiential learning

\section{INTRODUCTION}

The area of service science education progresses and is a subject of active research [1]. Service science takes theories from many disciplines and puts them together through the service-dominant logic [2]. In recent years, there have been many initiatives for developing the university education programs in the directions of service science, e.g., NC State University, Taiwan, Porto, Twente, [3]-[6]. The need for service science education exists also in industry and especially in the IT industry where services is a popular concept (e.g., ITIL) [7].

In most cases, service science finds its place in the university curriculum as courses complementary to the traditional technology courses. Service science might be considered, in many technical schools, as a business-related class about understanding how to apply technical knowledge in business situations.

Our teaching approach is based on experiential learning. We believe that we cannot teach services without experiencing the problems that trigger the invention and the use of services in business. Services in the industry were developed to bring practical solutions. Hence, we let students experience the challenges in practice, find their solution, and position services as the concepts to be learned theoretically.

A central theory for our service-oriented approach is (soft) systems thinking (SST). We believe that the systemic paradigm is useful because it is a meta-discipline of the different patterns that show how to connect the fractioned knowledge from other disciplines. But the nature of SST is to show the big picture, which makes it abstract and general. The conversation in SST is much more "philosophical" than practical. To counter balance this, and be able to teach ST to students, we need to establish a systematical teaching approach with practical examples of the principles in context.

To integrate all theoretical aspects of the course, we have defined a systemic paradigm that includes and positions all the theories we use. "Soft" theories are closer to philosophy, linguistics, and psychology (e.g., systems thinking) than to theories such as the formal methods used in computer science. The advantage of presenting the concept of a systemic paradigm is to make explicit many implicit principles that students use when thinking and that can cause them reach fallacious results. For example, oversimplifying reality or underestimating human aspects in a technical solution.

Our research question is, How can we to teach a serviceoriented mindset to IT students (and possibly engineering students)?

Our focus is on one meta-principle of our teaching approach: the notions of principle, pattern, and practice. This metaprinciple enables us to explain how to make abstract principles concrete. We develop, from the abstract systemic serviceoriented paradigm, concrete teachable heuristics that students learn to apply in practice. We see principles, patterns, and practice as heuristics on different levels of abstraction and scopes of applicability (from most generic to most concrete). It is by going back and forth between these three levels that we teach students to reuse their thinking style in different contexts. We categorize these heuristics accordingly. We define the terms as follows:

- A principle is a generalized rule that applies in many contexts. For us, the principles we want to teach are SST and business theory.

- A pattern is a regular form or sequence discernible in the way in which something happens. Thus, a pattern is a 
sign of order from seemingly unconnected elements. For us, the pattern is a concrete systemic method developed in our lab to model hence to structure the world.

- Practice is the actual application or use of knowledge.

Our research project is a design science research (DSR) project following the Information Systems Research Framework [8]. The result of our DSR project is an artifact that answers both a practical and a research question. This paper is based on the course we gave during the 2016/2017 academic year. The DSR artifact is a description of a teaching approach that answers the research questions explicitly. In the categorization of Gregor [9], the contribution to the knowledge base is an analysis and a description of an approach for teaching service science, with the help of systems thinking and different business theories.

We validated our interpretations with two surveys during the semester with all students, and with semi-structured interviews after the end of the course with a small set of students. The purpose of the first survey was to understand the expectations and background of the students in the classroom. The purpose of the second survey was to test our hypothesis about how well our teaching method worked.

With the students from the current class, we also coconstructed the course for students of the following year. At the end of the semester, the students reviewed what they learned on the subject matter and the teaching staff reviewed what we learned about the teaching approach. We then "traded" and thought about possible improvements.
Our main findings are as follows:

- The human factor in the course - the professor and the guest lecturers - influenced the motivation of the students to take the course.

- The closer the context is to the students' experiences, the easier it is for them to understand it.

- It is easier for students to apply abstract theories (business concepts and systems thinking) in order to analyze new situations but only after many repetitions of the same systemic method.

The paper has the following structure. In Section 2, we describe the research methodology. In Section 3, we describe our teaching approach towards service-oriented business design. In Section 4, we present our findings from surveys with students. In Section 5, we discuss the open questions. In Section 6, we present related work. We conclude and give directions for future work on the topic in Section 7.

\section{Research Methodology}

We adopt the Information Systems Research Framework [8] to organize our research (see Fig. 1). The relevance of our research comes from the observation that the business environment has an increasing need for IT engineers with professional skills [10]. The research rigor stems from the knowledge base and the systematic application of theories and evaluation methods from the knowledge base. Our goal is to solve a practical problem and to contribute to the knowledge

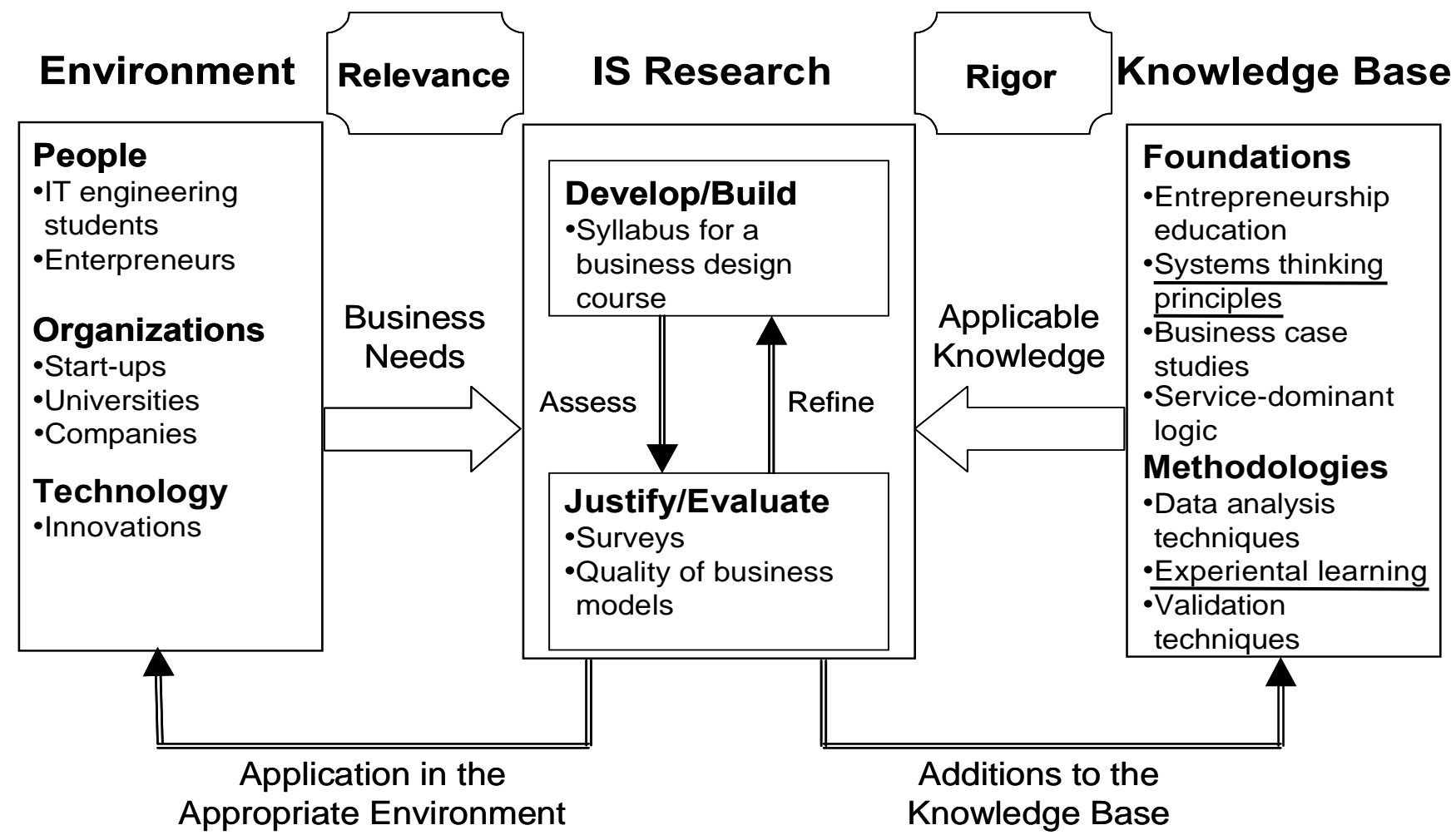

Fig. 1 Design science research project based on Hevner et al. [8] 
base with the help of an artifact: a service-oriented teaching approach to explaining business concepts to IT students.

The DSR framework has a two-fold purpose. First, we answer a concrete practical question that comes from the application domain. Our practical question is, How can we teach IT students service-oriented concepts so they can relate to their previous computer-science experience in understanding a business environment? Second, we address a research question, about how to teach abstract service-science principles to IT students and potentially engineering students. Our artifact is an explanation on how to teach service-oriented business design both systematically (in an ordered manner) and systemically (based on systems thinking). With our artifact, we contribute a theory of analysis and description [9] to the service-science educational literature.

The practical environment for our project is an elective course for the business design of IT services in the School of Computer and Communication Sciences at École Polytechnique Fédéral de Lausanne (EPFL) for master's students. Our involves people (IT students, entrepreneurs, teaching staff) and organizations (universities, companies, startups). This paper is based on the 2016/2017 academic year. 26 students attended the class. The duration of the course is 14 weeks in the spring semester (of a two-semester academic year). In addition to the teaching staff, there were six guest lecturers: four presented their own companies, one presented sales heuristics for helping customers discover the right service (based on [11]), and one led a creativity session "Lego Serious Play", where students used Lego metaphors to model their projects.

We draw our theoretical assumptions for creating the artifact from SST, service science, marketing, experiential learning, embodied cognition, and educational theories. To evaluate the artifact, we use a selection of qualitative evaluation methods: surveys and interviews [12].

We conducted two surveys - one in the fourth week and one in the last week of the class. 26 students responded to the first survey and 22 responded to the second. After the end of the class, we interviewed three students on their overall impression, motivation, acquired skills and knowledge, and the future evolution of the class.

\section{SERVICE-ORIENTED BUSINESS DESIGN - OUR TEACHING APPROACH}

We use principles from three fields - soft systems thinking, service science, and marketing (see Fig. 2). The pattern we present to the students, which connects the various principles is

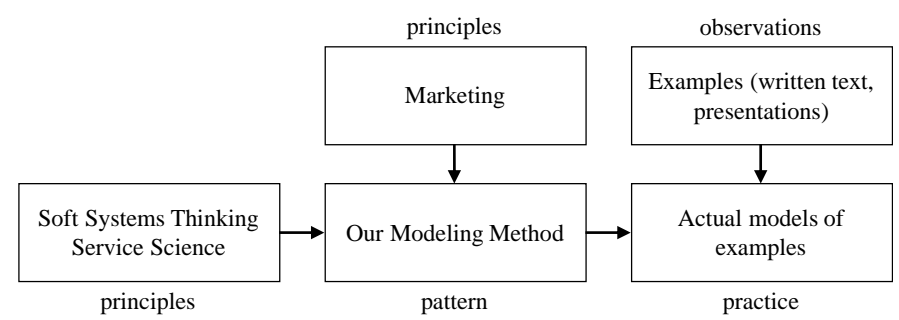

Fig. 2 Service-oriented teaching approach a service-oriented modeling methodology. Lastly, we use different examples and cases to apply the methodology.

\section{A. Principles}

(Soft) Systems Thinking is an interdisciplinary metaapproach that, broadly speaking, views everything as a system with many interrelated elements. The systemic paradigm is a philosophical standpoint with its epistemology, ontology, and axiology. The systemic epistemology determines how we know what we know, or in other words, the relationship between observed reality and the models. By ontology, we mean what exists in the model. And by axiology, we mean what the ethical choice of the modeler is in order to represent some parts of the observed reality but not others, or what the relationship between the modeler and the model is. Axiology is divided in two categories: ethics (the study of what good and bad are) and aesthetics (the study of the nature of art, beauty, and taste).

Service science is an interdisciplinary discipline, similar to and partially based on soft systems thinking, in its views of reality in connected systems. The focus of service science is on analyzing the business environment. Originally, the underlying logic of service science, the service-dominant logic as an alternative to product-dominant logic, emerged from marketing.

Our running examples are based on the two following heuristics: (1) moving the company's perspective, which entails shifting the strategy of the company to focus on the customers instead of on the product [13], and (2) changing the marketing strategy of a company, which entails a non-trivial change in a company's value network configuration [14] (the counter argument to the first heuristic).

These heuristics are abstract as they are generalized to apply in many situations (as we mentioned previously, a principle applies to many contexts). We still believe that systems thinking and service science are useful to IT and engineering students because these principles provide a framework for investigating business cases, real-world settings and, ultimately, for helping students analyzing and understanding their roles and opportunities in their professional lives after university. For this purpose, we present these principles on a lower abstraction level to students so they can relate to the principles and embody their knowledge as tacit.

\section{B. Patterns}

To help students understand the systems thinking and service-science principles, we use a systemic modeling method called SEAM [15]. SEAM is an instance of a systemic method adapted for modeling human-centered service systems. SEAM has been developed by our research group for the last 20 years. As we abide by the systemic paradigm, we worked on the three philosophical foundations (ontology, epistemology, axiology) of a conceptual modeling methodology.

\section{1) Ontology:}

The SEAM ontology consists of two types of models - a canvas and a supplier-adopter relationship (SAR) model [16]. The two models are complementary. The canvas, called a service system model, shows the service and the different actors, e.g., partners, competitors, influencers. The SAR model focuses 
on the relationship between a service supplier and a service adopter. The service has features that correspond to the adopters' benefits on one side, and the features are provided by components provided by the suppliers and their partners.

\section{2) Epistemology}

The epistemology of SEAM is influenced by the constructivism and interpretivism principles. We encourage students to engage actively in the learning process and to reflect on their experiences. The construction of knowledge in modeling human-centered service systems is an important part of understanding the environment. SEAM recognizes the subjective aspect of modeling in the relationship between a model and observed reality through the prism of a modeler. And with the help of epistemological principles, we explain to students how to recognize this relationship.

The epistemological aspect of our modeling methodology prompts students to connect their concrete observations (an exact piece of information, e.g., "I heard the adopter complain about not having enough time in the morning because the public transport schedule is inconvenient") to their statements (e.g., "a benefit for the adopter is to save time in the morning"). Furthermore, we teach students basic ethnographical principles on how to observe without interpreting, and how to collect evidence, e.g., notes, pictures, emails, recordings, to support their quest in modeling a situation.

Instead of providing explicit rules for modeling, our methodology includes heuristics to guide the modeling process. For example, a heuristic we give to students is to analyze the cases through the lens of "the customer of their customer". This means, that the scope of observation and understanding includes the ecosystem of our service adopters and their service adopters. If we observe only the ecosystem of a single service, we could have difficulties understanding the motivation of our adopters as their adopters' influence what our adopters would like to achieve.

\section{3) Axiology}

The axiology of SEAM relates to the choices we make as modelers and accounts for the subjective factor of modeling. Even though two service modelers might have similar goals and observations in modeling a case, axiology helps us understand why the models differ due to their experiences and backgrounds. SEAM, as a modeling methodology, gives guidelines to not create models for the sake of modeling, rather to help people communicate and make explicit their implicit inner mental maps. We teach students to use the systemic paradigm to understand what is valuable to them, as modelers, and to the people involved in a service exchange process.

\section{Practice}

The practice in our approach is the application of acquired knowledge and first-hand experience that students have in different contexts. We apply the pattern (SEAM) to various cases in order to analyze and to model them, and we connect the experience through reflection and generalization to the principles. The practice level is the most concrete one, where students instead of the teacher are the driving force.
The practice is based on observations that students make during the exercises - either guest lecturers' presentations, or their own group projects. The observations of the real world tie to the epistemological foundations of our method, where students have to observe how they observe and create their assumptions.

\section{Content Delivery}

We use experiential learning [17] to structure our content delivery. Kolb's experiential learning cycle has four steps concrete experience, reflection, generalization, repetition. According to the corresponding step from Kolb's cycle, we schedule the content of the course from the three different categories (principles, patterns, practice).

- Experience: observe and experience different contexts. During the semester, we present to the students the examples from the different papers, three case studies on Amazon that we composed, the businesses presented by guest lectures, and a group project.

- Reflection: use SEAM models and heuristics to structure (model and explain) the observed universe of discourse in a service-oriented way.

- Generalization: systemic principles, service-dominant theories.

- Repetition or another experience.

We take under consideration two additional factors in designing the course: the theory of embodied cognition and spaced repetition.

Barsalou [18] shows that cognition is an inseparable part of the brain's modal parts for perception, i.e., verbal, motion, vision. Furthermore, in a constructivism view, the learner and the educator are both facilitators in the knowledge creation process [19]. The cognitive distance to a subject is important for developing confidence (by applying a known cognitive schema) and creativity (by exploring unknown territories and creating new cognitive schemas) [20], [21]. To evaluate how they felt about it, we look further into the cognitive distance between the students mental maps and their perceptions.

The second theory we use is about spaced repetition as a means to achieve automaticity (or repetition priming) [22]. We consider three major characteristics:

- The more times a stimulus has been encountered, the faster an individual reacts to it. We repeat as often as every week the same activity (service-oriented analysis) with different case studies.

- The benefit of repetition is still dependent on an individual's traits.

- The associations between the stimuli and the contextual interpretations influence the benefit of repetition. As we follow an experiential learning cycle, we reflect on the experiences after each activity, hence, we create these associations. 


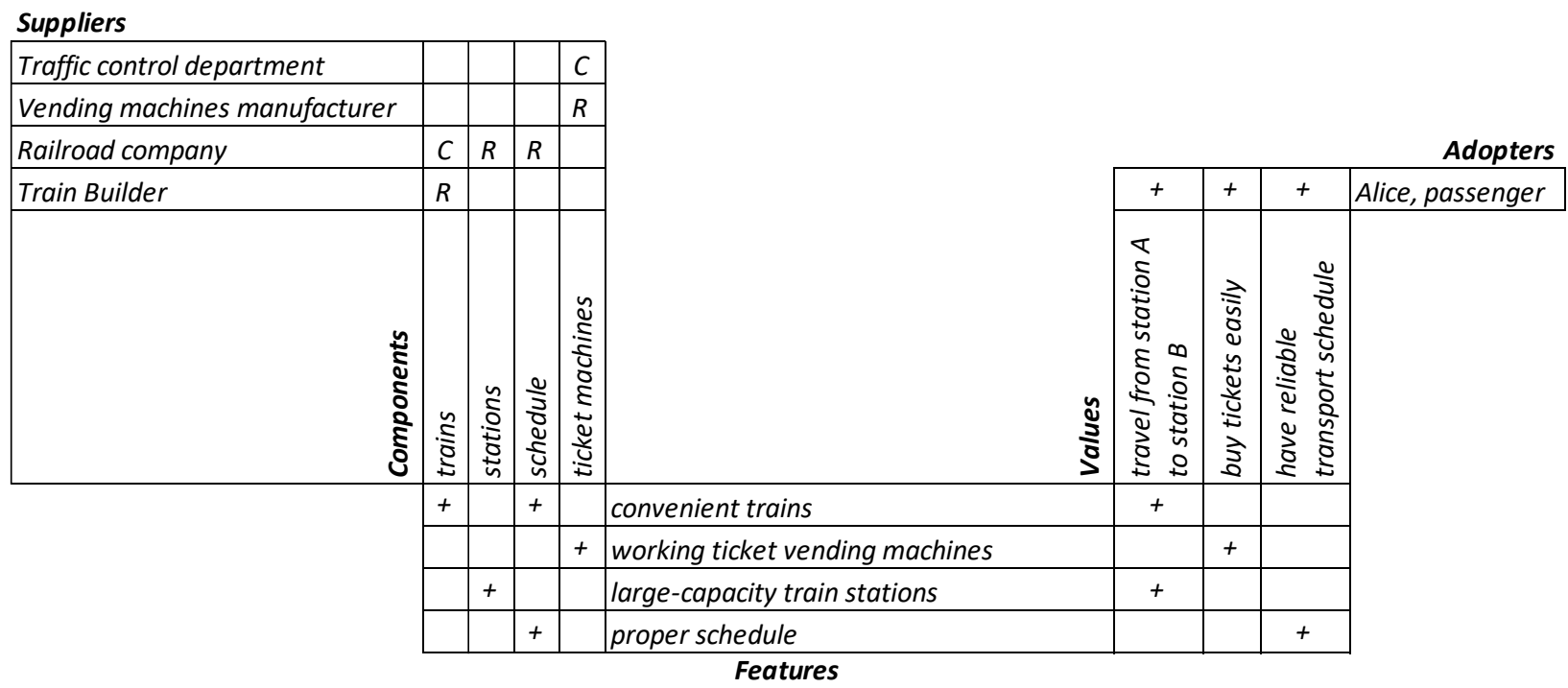

Fig. 3 Product-oriented SAR model of the railroad business

\section{E. Example-Marketing Principles through the Service Science Lens}

To illustrate our teaching approach, we use an example of how we use the heuristics from the marketing literature [13] and [14], together with a service-oriented toolkit. Levitt [13] questions the product-oriented approach of companies and calls for a change to a customer-orientated mindset. This deceptively simple change of perspective leads a chain of cultural and organizational changes [14]. The word "product" has a connotation of an item to sell; with such a sales-centered point of view, a company "speaks" the language of manufacturing and production (quotas, and sales forecasts) and not the language of customers (values, benefits, needs, use).

Our modeling methodology includes the SAR model, with analysis of corresponding components provided by a service supplier, the features of the service, and with benefits for a service adopter. Figure 3 depicts the product-oriented example of the railroad industry from [13]. In this model, Fig. 3, we see that the main service offering of the service providers includes the infrastructure for railroad - stations, rails, trains. The service adopter is a passenger on a train, and the reason for traveling remains unknown. The only motivation that the service provider considers is that the passenger wants to go from Station A to Station B. The partners of the railroad company (or in service science terms, the value network that provides value to the service adopter through a service collaboratively) includes the state, the ticket vending machine manufacturer, the traffic control department, etc. We see how their alliances, as in this model, differ considerably from the value network necessary for shifting from a product-oriented to a customer-oriented perspective.

Fig. 4 depicts the second model, or the customer-oriented service system. In this model, the service adopter is a traveler. The modeling process starts with understanding the benefits of travelling from Destination A to Destination B. The scope of this

Suppliers

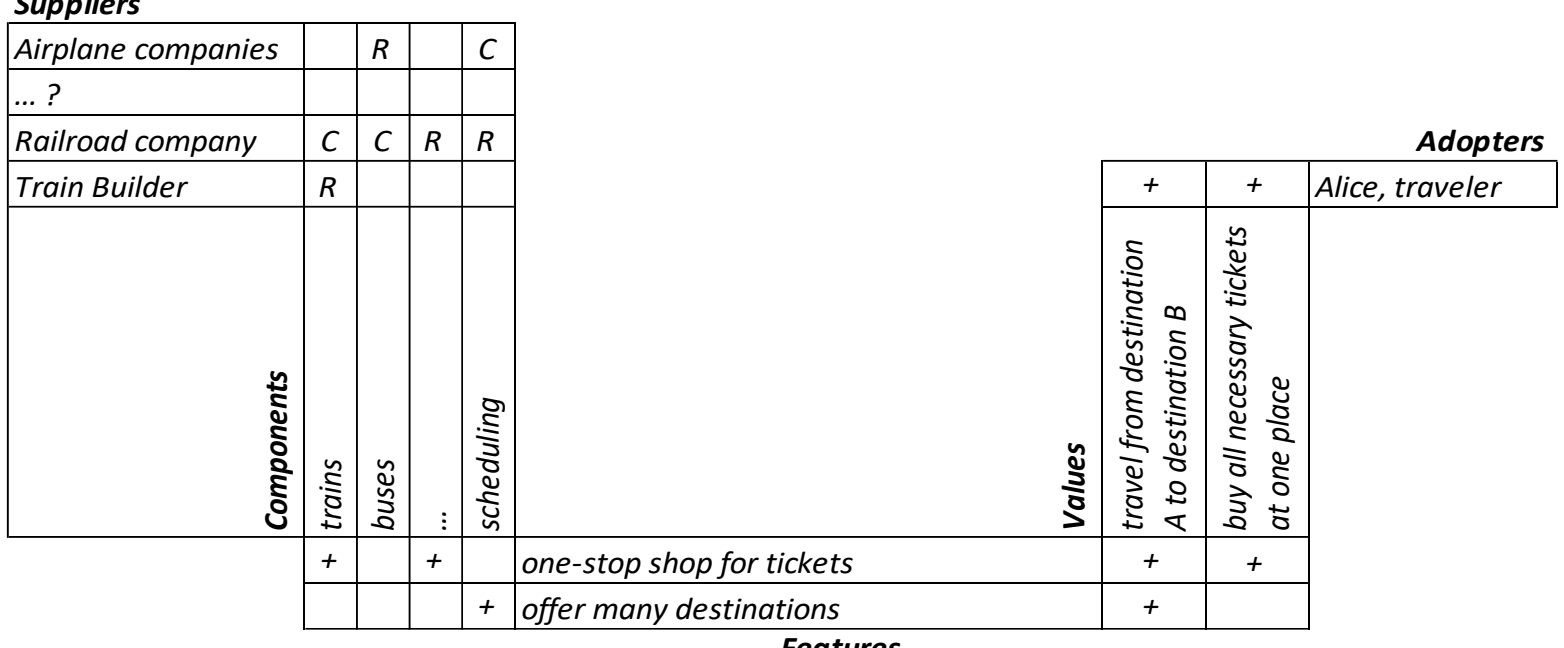

Features

Fig. 4 Customer-oriented SAR model of the railroad business 
transit expands because travelling from Station A to Station B is a part of a larger journey. The full package needs to include other means of transportation, i.e., airplanes, buses, taxis. The features of the service are a direct response to the benefits for travelers.

Students begin by analyzing the value network of the supplier and, only afterwards, they model and conceptualize who will benefit and how from the service. The example shows primarily the stark difference between conceptualizing what is already assumed to be known (a railroad company provides trains and stations) and asking questions to obtain new information ("Why would a person travel to a station?")

Ahlstrand et al. [14] questions the change in perspective from a product-oriented company to a customer-oriented company and the necessary capabilities for facilitating the change. The corresponding business heuristic is based on a principle in systems thinking: the regulatory principle that every system tries to preserve its state (homeostasis); and to do so, the system opposes any change that can bring its inner state to inconsistency.

In the SAR model we observe the differences in the value networks for the two situations. Using these models, we analyze the required change: is it only slightly different or is the change significant? If the change is major, a company might have to explore a territory that is beyond its competence and capabilities. We relate this change to the epistemological bases of knowledge: If a company has no observation over a certain portion of reality, it can have little to no conceptualization of this reality. Hence, it would be nearly impossible for it to even perceive the possibility of change, much less to actually make the change.

\section{RESULTS}

\section{A. First Survey}

We conducted the first survey during the fourth week (out of fifteen weeks). All students participated in the survey (26 in total). The main goal was to collect opinions on the expectations, background, and motivation of the students who took the course (results in Fig. 5).

\section{Students' Motivation to Take the Course}

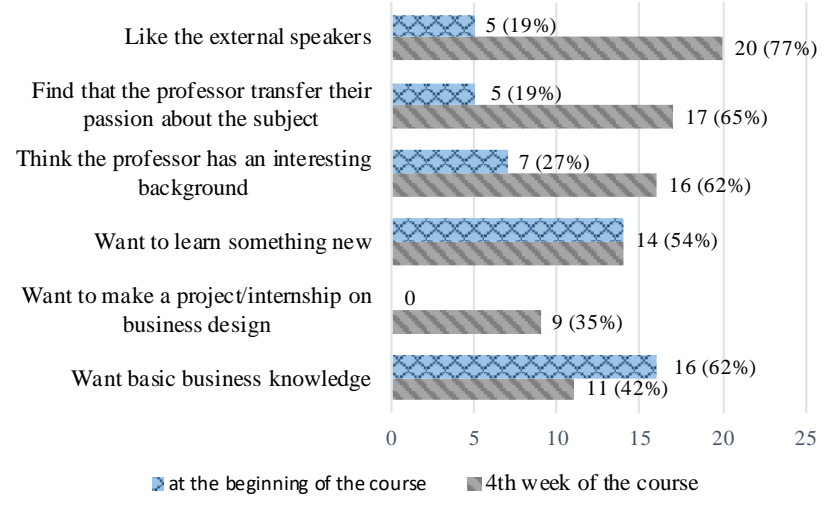

Fig. 5 Motivation and expectations of students
At the beginning, most students decided to take the course because they wanted basic business knowledge. However, at the time of the survey (fourth week), the desire for basic business knowledge decreased. The main reasons the students continued with the course were the presence of guest speakers, and both the professor's interesting background and his passion for the subject.

After the fourth week, the number of students who have an interest in learning something new is the same. This gives us grounds to believe that the students expect that there will continue to be something new to learn from the course. We find it intriguing that at the beginning of the class no student indicated that they wanted to pursue a project or an internship in the domain of business design. In their fourth week, however, nine students said they were interested in doing this.

In addition, we asked students to give their opinion on their preferred learning activities. The activities most liked were analyzing case studies to understand business concepts in context and working in a group to develop their own ideas. The most disliked activities were theoretical lectures and presentations in front of the class.

\section{B. Second Survey}

We conducted the second survey during the last lecture of the course (fourteenth week). 22 students participated in this survey. We asked them questions in categories: on the activities they liked (see Fig. 6) and what knowledge they felt they had acquired (see Fig. 7). All questions follow this scale: $1=$ Strongly disagree, 2 = Disagree, $3=$ Neither agree, nor disagree, $4=$ Agree, 5 = Strongly agree.

\section{Activities Students Liked}

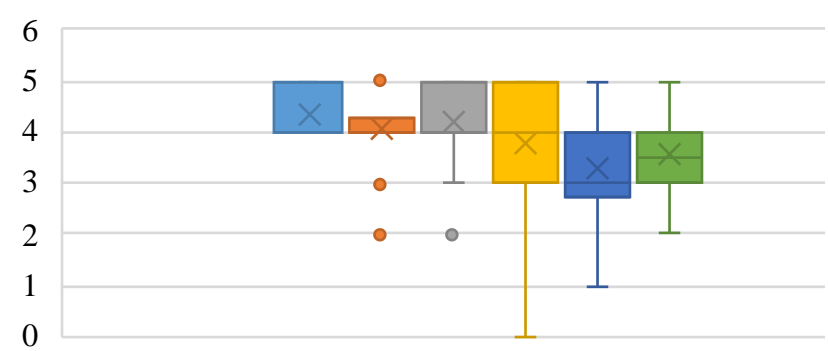

Analysing the speakers' business plan

Studying cases (Amazon, MVI)

Presenting our team project

Creating the prototype for our project

Modeling our project on online platform

Getting feedback

Fig. 6 Activities that students liked during the course

The activities most liked were the experiential activities: the three top activities are analyzing the speakers' business plans (mean $=4.4)$, studying the practical cases $($ mean $=4.0)$, and working on their own project (presenting with mean $=4.2$ and 
prototyping $=4.0)$. The activities students disliked were modeling their assignments in the online platform ( mean $=3.3$ ), which support our modeling exercises, and receiving feedback on their models (mean = 3.6).

The next set of questions probed what students believed they had learned and understood from the course (see Fig. 7). For a start, students gave the highest value to the difference between product-oriented (or goods-dominant) and service-dominant logic (mean $=4.5)$. The other take-away from the course was the thinking model that students would reuse $($ mean $=4.1)$. Students understood the relationship between different parts of the course, e.g., examples, case studies, the group project, papers, etc. (mean =4.1). Students had difficulties understanding the idea of principles, patterns, and practice $($ mean $=3.2)$, relating concepts

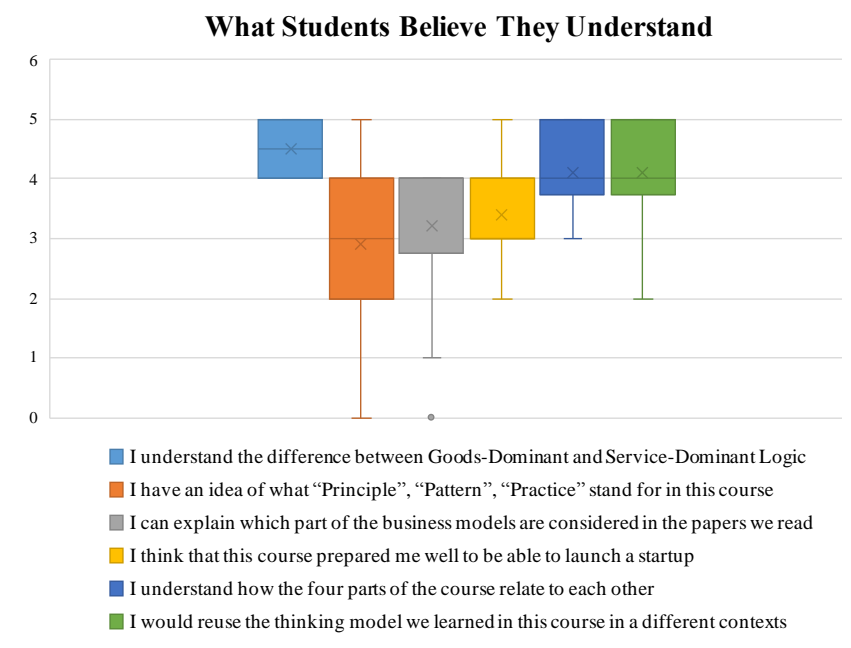

Fig. 7 Knowledge that students believed they acquired

from the course to the read business papers (mean $=3.4)$, and launching a startup (mean $=3.4)$.

\section{DISCUSSION}

\section{A. Structure of Knowledge}

1) Principles, Patterns, and Practice as a Way to Connect Different Fields

The results from our second survey report that students could not understand what we meant by principles, patterns, and practice. From this, we learned that we have to explicitly explain our teaching approach to the community and to our students. This paper is based on a previous course in which we did not present these ideas to the students, rather we expected to build the knowledge and understanding with them. We acknowledge the limitations of the constructivist teaching style. We decided to guide the students of next year's classes towards the metaprinciples.

Nevertheless, students acquired knowledge about how to relate different fields, and they adopted the mindset of the service-dominant logic, which was our goal. Due to their answers on the exam, we believe they have embodied serviceoriented thinking.

\section{2) Emotional Proximity}

We also observe that the emotional proximity to the context influences the engagement of the students; the closer the context is, the easier it is for students to immerse themselves in the details. Third, a great part of the outcome for engineering students in these non-engineering classes depends on their tolerance of uncertainty.

It is only by practicing that we can acquire or perfect a skill. Many people are uncomfortable experimenting something they are not familiar with, this phenomenon not exclusive to students. But as our students are in our classroom to learn something new, we try to make them experience unfamiliar settings that put them outside of their comfort zone. Students practice analyzing the environment by, for example, writing down explicitly their assumptions, talking to people to collect information, working in a team, handling interpersonal relationships, and presenting in front of a public. Even unwillingly, they can acquire feedback form the environment and construct mental models.

We, as humans, have cognitive maps that help us deal with complexity [23]. We observe in the classroom that students prefer exercises with cases closer to their personal context. For example, a bed manufacturer (with a business background) presented their company to the class. He put a strong emphasis on the difference between typical beds and his smart beds (with sensors in the beds, data analytics, mobile applications). The students preferred, however, the presentation by an ex-IT student who started a burger company with friends, without any technology behind the burger business. The burger company has a venue on campus. After the presentations, the students modelled the businesses, while the speakers were available to answer questions. Even if we account for the difference in personality and presentation style, our survey shows that students prefer to work on cases in which they can imagine being a part of (such as the burger company).

Indeed, one of the preferred presentations was the one given by a student from the same master's program. The speaker started a company with a friend and worked on it in addition to their studies. Students can imagine themselves running a small company, in addition to their studies, more easily than imagining themselves being the CEO of a company such as Amazon.

\section{3) Uncertainty}

We observe a certain correlation between how much students benefit from the course and their tolerance towards uncertainty. Most of the frustration in the life of an entrepreneur comes not from risk but from uncertainty [24]. Tolerance for uncertainty is hard to cultivate in a classroom environment but this is possible. The classwork in our course is of such nature that there are no absolute correct answers. We encourage students to explore the cases by asking questions and imagining situations. With this approach, the teachers are not able to say that a model is (in)correct. The students have to explain their reasoning and support it with evidence. Our goal is to help students become confident in their own knowledge. All this stems from the constructivism view of the learner as an active participant in the knowledge creation process. 


\section{B. The Pitfall: "If the only instrument you have is a hammer, all problems are nails"}

The systemic paradigm is not a panacea for solving problems. It is a way to look at the world and see connections between scattered pieces and to give meaning to what we see. We emphasize, however, the need to understand the subjectivity of service science and systems thinking. Models are dependent on the observer/modeler and their subjective interpretation of the world, their goals, and their experience.

Moreover, service-oriented and product-oriented mindsets can complement each other in a beneficial way. In the business and academic settings, every successful project needs both depth and breadth. Service-dominant and product-dominant logic can contribute to these different parts.

\section{Course Co-creation with Students}

Students felt they had an effect on the course's content and its structure because we collected feedback from them, discussed our interpretations, and communicated the changes that stemmed from this process. This technique is nothing new in the world of business, where companies use co-creation techniques to stimulate the customers' long-term loyalty. Our initial idea was to use the surveys as an instrument to understand our students and to devise a course that fits their needs and expectations. But the added benefit was that students became involved in the course and felt ownership.

\section{PREVIOUS AND RELATED WORK}

The content for existing service-oriented courses can be broadly categorized in three types: (1) introductory course to service science, (2) service management, and (3) service engineering [25]. Our course combines these three content types. We include service strategy, service design, and service operations in the term service management [26]. We also explain the meaning of these services in terms of logical reasoning (to analyze motivations), behavioral semantics, and refinement theories (to analyze service structure). Non-computer-science students can take our courses but computer-science students will relate more to the "underlying" theory of services.

This paper completes a previously published short paper [27]. In our previous work, we presented our assumptions on how to relate principles, patterns, and practice, what content to choose based on the emotional distance to students, and how to deliver the course based on experiential learning.

We apply this teaching approach in a second course, called Enterprise and Service-Oriented Architecture, delivered by our research group. We have previously shown the benefits of experiential learning [28] and the role of ethnographic methods in the classroom [29].

\section{FUTURE WORK AND CONCLUSION}

In this paper, we have presented our teaching approach towards service-oriented business design. The approach is based on the notions of principle, pattern, and practice. We have described these three levels of abstraction. We have presented the results from two surveys we conducted with our students during the spring semester of the 2016/2017 academic year. Our main findings are that students understand and adopt the serviceoriented mindset after taking the course, and that the human factor (lecturers, teaching staff, and the professor) is important for students to relate to the new knowledge, and to be able to embody it.

We are actively re-designing our courses to reflect the findings and to answer the industry needs for skilled wellrounded IT specialists and the university's requirements for systematical education beneficial to students, and more to society. We are developing a set of complementary materials, e.g., videos, cartoons, and case studies. With this paper we hope to clarify the underlying reasoning behind our teaching approach, as well as the results from our students' feedback.

\section{ACKNOWLEDGEMENTS}

We thank Gil Regev and Gorica Tapandjieva for their insights and support during the project. We thank Laurence Duré for her assistance with the surveys. We thank Solal Pirelli for his comments that greatly improved the manuscript.

\section{REFERENCES}

[1] J. Spohrer and P. P. Maglio, "The emergence of service science: Toward systematic service innovations to accelerate co-creation of value," Prod. Oper. Manag., vol. 17, no. 3, pp. 238-246, 2008.

[2] R. F. Lusch and S. L. Vargo, The service-dominant logic of marketing: Dialog, debate, and directions. Routledge, 2014

[3] J. F. Cunha, L. Patrício, A. Camanho, and R. Fisk, A Master Program in Services Engineering and Management at the University of Porto. 2008.

[4] K. M. Wang and T. Shin Sheu, "Developing Service Science Curricula for Industrial Engineering and Management Education in Taiwan," in Asia Pacific Industrial Engineering and Management Systems Conference, APIEMS, 2009, pp. 94-100.

[5] S. Allen et al., "Service science, management and engineering curricula and research at NC state university," in Service Science, Management and Engineering Education for the 21st Century, Springer, 2008, pp. 129-136.

[6] V. Sorathia, L. F. Pires, M. van Sinderen, and F. Wijnhoven, "Developing a Services Science Graduation Programme at the University of Twente," in Transforming Engineering Education: Creating Interdisciplinary Skills for Complex Global Environments, 2010 IEEE, 2010, pp. 1-18.

[7] S. Cavalieri, M. Rapaccini, G. Pezzotta, and N. Saccani, "Research and Education in Service Science Management and Engineering: The Case of the Italian Service Management Forum," in International Conference on Exploring Services Science, 2016, pp. 750-760.

[8] A. R. Hevner, S. T. March, J. Park, and S. Ram, "Design Science in Information Systems Research," MIS Q., vol. 28, no. 1, pp. 75-105, 2004.

[9] S. Gregor, "The nature of theory in information systems," MIS Q., vol. 30, no. 3, pp. 611-642, 2006.

[10] L. J. Shuman, M. Besterfield-Sacre, and J. McGourty, "The ABET 'Professional Skills' - Can They Be Taught? Can They Be Assessed?," J. Eng. Educ., vol. 94, no. 1, pp. 41-55, 2005.

[11] D. Mattson, “The Sandler rules,” Beverly Hills: Pegasus Media, 2009.

[12] M. Q. Patton, Qualitative evaluation and research methods. SAGE Publications, inc, 1990.

[13] T. Levitt, "Marketing Myopia,” pp. 1-25, 1975.

[14] B. Ahlstrand, J. Lampel, and H. Mintzberg, Strategy Safari: A Guided Tour Through The Wilds of Strategic Mangament. Simon and Schuster, 2001 
[15] A. Wegmann, "On the systemic enterprise architecture methodology (SEAM)," in International Conference on Enterprise Information Systems, 2003.

[16] A. Wegmann, P. Julia, G. Regev, O. Perroud, and I. Rychkova, "Early requirements and business-IT alignment with SEAM for business," in Proceedings - 15th IEEE International Requirements Engineering Conference, RE 2007, 2007, pp. 111-114.

[17] D. A. Kolb, Experiential learning: experience as the source of learning and development. Englewood Cliffs, NJ: Prentice Hall, 1984.

[18] L. W. Barsalou, "Grounded Cognition," Annu. Rev. Psychol, vol. 59, pp. $617-45,2008$.

[19] M. F. Aqda, F. Hamidi, and F. Ghorbandordinejad, "The impact of constructivist and cognitive distance instructional design on the learner's creativity," Procedia Comput. Sci., vol. 3, pp. 260-265, 2011.

[20] B. Nooteboom, W. P. M. Vanhaverbeke, G. M. Duysters, V. A. Gilsing, A. J. Van Den Oord, and B. Nooteboom, "Optimal cognitive distance and absorptive capacity," 2005.

[21] B. Nooteboom, "Learning by interaction: Absorptive capacity, cognitive distance and governance," J. Manag. Gov., vol. 4, no. 1-2, pp. 69-92, 2000.

[22] G. D. Logan, "Repetition priming and automaticity: Common underlying mechanisms?," Cogn. Psychol., vol. 22, no. 1, pp. 1-35, 1990.
[23] C. Eden, "On the nature of cognitive maps," J. Manag. Stud., vol. 29, no. 3, pp. 261-265, 1992.

[24] A. V Bhidé, The origin and evolution of new businesses. Oxford University Press, 2003.

[25] J. Wei, J. Chen, and Q. Zhu, "Service Science, Management and Engineering Education: A Unified Model for University," in Technological Applications and Advancements in Service Science, Management, and Engineering, IGI Global, 2012, pp. 134-151.

[26] R. J. Gluschko, "Designing a service science discipline with discipline," IBM Syst. J., vol. 47, no. 1, pp. 15-28, 2008

[27] B. Kostova, G. Tapandjieva, and A. Wegmann, "Teaching Business Design at an Engineering School-Principles/Patterns/Practice," in ISPIM Innovation Symposium, 2017, p. 1.

[28] G. Regev, D. C. Gause, and A. Wegmann, "Experiential learning approach for requirements engineering education," Requir. Eng., vol. 14, no. 4, pp. 269-287, 2009.

[29] G. Regev, L. Regev, Y. Naïm, J. Lang, and A. Wegmann, “Teaching an ethnographic approach to requirements elicitation in an enterprise architecture course," in CEUR Workshop Proceedings, 2015, vol. 1374, pp. 5-19. 